drawal and be virtually immobile. Posturing and mannerisms are often seen, the child spinning and rocking in the most remarkable manner. Obsessional play with water, bricks, and other toys is a common symptom, the child showing considerable anxiety and aggression when the pattern of play is disturbed. Intellectually the child may be retarded, but fairly commonly-though formal testing of intelligence is often impossible-he appears to be behaving in a manner indicative of at least average intelligence.

The frequency of this condition is not clearly known, for some autistic children are still being diagnosed as subnormal. J. K. Wing, N. O'Connor, and V. Lotter, ${ }^{2}$ at the Social Psychiatry Research Unit at the Maudsley Hospital, undertook a survey of Middlesex children aged 8, 9, and 10 and found that there were $2 \cdot 1$ per 10,000 with severe autism and a further 2.5 per 10,000 who displayed some of the features associated with it. If these figures can be regarded as representative of the country as a whole, there would be 3,000 children suffering from autism.

The aetiology of psychosis in childhood remains obscure. Psychogenic and biochemical causes have been discussed, while some workers consider that perceptual difficulties may be at the root of the disease. Much more research is needed into its aetiology.

The facilities for treating and educating psychotic children are extremely limited. Formal education is not necessary or possible, but "therapeutic education" is helpful. It may be based on "operant conditioning," by which the child is rewarded for giving correct responses while incorrect ones are dealt with by punishment, disapproval, and the withholding of reward. In another method, used at a day unit set up by Surrey County Council Education Authority, the child is free in the early stages to follow his own desires and no pressures are brought to bear. An attempt is made to turn the child's mannerisms into some useful act, and in this way a relationship begins to form between child and teacher. Improvement with all psychotic children is of necessity slow, and at present the outlook is far from hopeful in many cases.

There is still no unanimity on whether these children should be in day or residential units. When the child is a disruptive influence in the home and is causing distress to the parents or to other children, or when there is a domestic crisis, residential placement is a necessity. But if the home is good and secure, day attendance would be preferable. There are too few places in special units and classes for these children, while the hospital service has too few beds for those who are severely disturbed. Many are sent to institutions for the mentally subnormal when they cannot be contained at home or in special schools. More facilities for education and treatment are urgently required.

\section{Vaccines up the Nose}

A vaccine against the common cold has been sought for years. Though many of the causal organisms can now be grown, and intramuscular injection of a killed vaccine has been shown to give some protection, ${ }^{12}$ a useful vaccine seems as far off as ever. One reason is that there are numerous serotypes, particularly of rhinoviruses-a few more were reported very recently ${ }^{3}$-and it is expected that the total of recognized serotypes will exceed 90 during 1970. Another reason is that some vaccines stimulate the formation of antibody against the organism but do not protect against infection or illness.

Such a vaccine has recently been the subject of some studies by J. C. Perkins and colleagues. ${ }^{4}$ The vaccine, in which the virus had been inactivated, was instilled into the nose in $0.2 \mathrm{ml}$. drops repeatedly for an hour. This procedure was repeated thrice at intervals of one week and finally after two weeks. The volunteers who took part in this test were known beforehand to be free of antibody against rhinovirus type 13. They were bled and nasal washings were collected at intervals. After four administrations 14 of the 17 volunteers had a significant increase of antibody in the nasal secretions and in the blood or in either; five had a fourfold increase in nasal antibody. All were then given living virus by intranasal drops and were found to be partially protected, in that only four out of 12 vaccinated persons became ill while 11 out of 13 unvaccinated persons did so. Roughly the same titres of serum antibodies were produced by giving the same vaccine intramuscularly to other volunteers, but they were not protected.

This is another useful piece of evidence to support the view that nasal antibody, mostly $\operatorname{IgA}$, is an important factor in protection against respiratory disease. ${ }^{5-8}$ However, in order to prevent the colds in this experiment $8 \mathrm{ml}$. of vaccine was used, and the vaccination sessions took a total of four hours. This may dampen what seemed to be a renewed interest in giving killed vaccines up the nose, though J. J. Mann and colleagues ${ }^{9}$ had revived the idea by inducing production of nasal antibody and, apparently, resistance to natural infection with influenza $\mathrm{A} 2$ virus by spraying killed vaccine up the nose and throat in substantial amounts-a total of $4 \mathrm{ml}$. in two administrations. At a recent meeting in Atlanta to review the first Hong Kong influenza epidemic, experiments on volunteers were reported by A. S. Beare. ${ }^{10}$ He had sprayed influenza $B$ vaccine up the nose and exposed the volunteers to a live virus to discover whether they were immune. He found no protection after one dose of $1 \mathrm{ml}$., the amount which gave good protection when injected intramuscularly; he seemed to have produced some protection after two doses up the nose, but the numbers were small. At the same conference $P$. Small ${ }^{11}$ reported limited protection against Hong Kong influenza from two doses of intranasal vaccine. The intramuscular vaccine, too, was only of limited value. This may have been because the virus was new; hence the people who received the vaccine, not having previously been infected with a related organism, lacked immunocytes in the nose ready to respond to antigen brought to them from the intramuscular deposit of the vaccine.

\footnotetext{
1 Mufson, M. A., et al., fournal of the American Medical Association, $1963,186,578$

Scientific Committee on Common Cold Vaccines, British Medical Fournal, 1965, 1, 1344.

3 Stott, E. J., Eadie, M. B., and Grist, N. R., American fournal of Epidemiology, 1969, 90, 45.

4 Perkins, J. C., et al., American fournal of Epidemiology, 1969, 90, 319. 5 British Medical fournal, 1969, 2, 712.

Bellanti, J. A., Artenstein, M. S., and Buescher, E. L., fournal of Immunology, 1965, 94, 344.

7 Smith, C. B., Bellanti, J. A., and Chanock, R. M., Fournal of Immunology, 1967, 99, 133.

8 Cate, T. R., Rossen, R. D., Douglas, R. G., Jr., Butler, W. T., and Couch, R. B., American fournal of Epidemiology, 1966, 84, 352

9 Mann, J. J., et al., fournal of Immunology, 1968, 100, 726.

10 Beare, A. S., Bulletin of the World Health Organization, in press.

11 Small, P., Jr., Contribution to International Conference on Hong Kong Influenza, Atlanta, Georgia. 1969.
} 
Whatever the explanation, the facts are clear. Nasal vaccination can induce immunity to respiratory infection, but more vaccine is required, and it must be given more often, than by intramuscular injection. This is certainly of theoretical interest, and efforts may still be made to induce immunity in this way in special cases-for instance, when parenteral injection would be harmful, as in the vaccination of infants with respiratory syncytial virus. It is more likely to stimulate a further search for acceptable living intranasal vaccines and improved parenteral ones.

\section{Trigeminal Sensory Neuropathy}

In 1935 Wilfred Harris ${ }^{1}$ described a disorder characterized by transient disturbance of sensation in the distribution of one or more divisions of the fifth cranial nerve, and he pointed out that in some cases the resolution of sensory loss was followed by the development of trigeminal neuralgia. T. R. Hill ${ }^{2}$ noted two similar cases but with the motor division of the affected trigeminal nerve also involved and an associated Horner's syndrome on the same side. B. Hughes ${ }^{3}$ reported a further three cases of trigeminal neuropathy in which the onset of facial sensory loss was heralded by pain of a similar distribution. Then J. D. Spillane and C. E. C. Wells ${ }^{4}$ described a series of 16 cases of isolated trigeminal neuropathy. In one of these patients sensation gradually recovered over a few weeks or months, but in others numbness and objective sensory loss persisted, though no other signs of neurological disease developed.

Now J. N. Blau, M. Harris, and S. Kennett ${ }^{5}$ report a series of ten patients each of whom complained of painless numbness on one side of the face. The sensory disturbance was usually noticed on awaking or while shaving or applying lipstick, and many patients described the sensation as being like that resulting from dental anaesthesia. The symptoms were confined to the territory of the second division of the trigeminal nerve in one case, to the third division in three cases, and both the second and third simultaneously in five. All three divisions were affected in only one patient. In no case was the motor division of the nerve involved, and the corneal reflex was invariably retained. Three patients with disturbance of the third division noted impairment of taste on the affected side of the tongue. On examination there was blunting of the appreciation of both pinprick and light touch in the affected area. In no case was there any other evidence of neurological abnormality.

Five of the ten patients recovered completely over periods varying from a few weeks to a few months, but in the remaining five the symptoms persisted over many months of observation. Radiological studies of the sinuses and base of skull were normal in all cases and serological tests for syphilis were negative, while the erythrocyte sedimentation rate was also normal. The postnasal space was examined with negative results in seven cases, and in two patients the cerebrospinal fluid was examined and was found to be normal in all respects.
The cause of this syndrome is obscure. In each of the three cases with a painful onset described by Hughes ${ }^{3}$ sensory impairment was inexorably progressive, and arachnoiditis round the trigeminal sensory root was found at operation. While it is certainly possible that some patients could have an early neuroma of the Gasserian ganglion, ${ }^{6}$ such tumours are rare. M. H. E. Seward, ${ }^{7}$ who described four cases, all ending in complete or partial recovery, suggested an analogy between this condition and Bell's palsy. Blau and his colleagues ${ }^{5}$ point out that transient paresis of one sixth cranial nerve, giving diplopia on lateral gaze to the affected side, is relatively common. When, as is usually the case, this develops in elderiy or atherosclerotic persons, it is usually attributed to atherosclerosis.

D. L. Knox and colleagues ${ }^{8}$ have recently described ten children under the age of 15 each of whom suffered a transient sixth-nerve palsy of three to six weeks' duration. They postulated a virus as the cause of this syndrome. To Blau and his colleagues this is an attractive hypothesis, and they raise the possibility that the trigeminal neuropathy which they describe, as well as the more common transient palsies of the abducens and facial nerves, could possibly have a similar aetiology. But no evidence to support this hypothesis is available.

In this context a remarkable case, also reported by Wilfred Harris, ${ }^{9}$ is of some importance. He described the case of a woman aged 47 who developed complete right-sided facial sensory loss with loss of taste on the affected side at the age of 21 . These sensory defects cleared up after one year, to be followed three years later by typical paroxysmal trigeminal neuralgia on the same side of the face and 14 years later by other symptoms and signs of multiple sclerosis. Though this case is probably unique, ${ }^{10}$ it is well to remember that transient trigeminal sensory loss may sometimes be due to a demyelinating lesion.

Despite the unknown aetiology of this interesting syndrome Blau and his colleagues ${ }^{5}$ give some useful practical advice on its investigation. They suggest that, if one or more sensory divisions of the fifth cranial nerve are affected and the corneal reflex is preserved, the postnasal space should be carefully examined, the erythrocyte sedimentation rate should be performed, syphilis should be excluded serologically, and radiographs of the paranasal sinuses and skull base should be taken to exclude other causes of trigeminal nerve disease. While the prognosis is in general good, particularly when the sensory disturbance is confined to the third division of the trigeminal nerve, if the motor division is also involved full neurological investigation in hospital with contrast radiography is indicated. Only in a small proportion of cases of trigeminal sensory neuropathy are other neurological symptoms to be expected, but long-term follow-up of these cases is likely to throw new light on the aetiology of the syndrome.

1 Harris, W., British Medical fournal, 1935, 1, 1112

Hill, T. R., Proceedings of the Royal Society of Medicine, 1954, 47, 914.

3 Hughes, B., Proceedings of the Royal Society of Medicine, 1958, 51, 529.

4 Spillane, J. D., and Wells, C. E. C., Brain, 1959, 82, 391.

5 Blau, J. N., Harris, M., and Kennett, S., New England fournal of Medicine, 1969, 281, 873.

6 Jefferson, G., Clinical Neurosurgery, 1955, 1, 11.

7 Seward, M. H. E., British Dental fournal, 1962, 113, 423.

8 Knox, D. L., Clark, D. B., and Schuster, F. F., Pediatrics, 1967, 40, 560 .

9 Harris, W., British Medical fournal, 1950, 2, 1015.

10 McAlpine, D., Lumsden, C. E., and Acheson, E. D., Multiple Sclerosis: $A$ Reappraisal. Edinburgh, Livingstone. 1965. 